\title{
The Profound but Often Forgotten Significance of Energy as a Measure of Change of State
}

\author{
Bryan Karney \\ University of Toronto, Canada
}

\begin{abstract}
Energy is perhaps one of few universally employed concepts, whether used by economists, environmental fundamentalists, physicists, chemists, biologists, biochemists, engineers, foresters or medical doctors. It is central to an evaluation of both sustainability and environmental impact, but also to very human things from the study or depression, to cooking, to athletic performance and longevity. Familiarity often means we believe we know these energy-related things well, but the specific energy definitions - as they often appear in books, papers and popular articles - seems to indicate that the profoundly universal nature of the concept of energy is missed, forgotten left somewhat vague. This presentation will first review the crucial and fascinating physical connections that give rise to the modern thermodynamic concept of energy. This general understanding will then be used to account for the undisputed role that energy plays transformations of everything from the photon given off from a single atom, to the dynamics of an ecosystem, to the evolution of a star system.
\end{abstract}

